\title{
A novel presence-only validation technique for improved Steller sea lion Eumetopias jubatus critical habitat descriptions
}

\author{
Edward J. Gregr*, Andrew W. Trites \\ Marine Mammal Research Unit, Room 247, AERL, 2202 Main Mall, University of British Columbia, Vancouver, \\ British Columbia V6T 1Z4, Canada
}

\begin{abstract}
We used published information about foraging behaviour, terrestrial resting sites, bathymetry and seasonal ocean climate to develop hypotheses relating life-history traits and physical variables to the at-sea habitat of a wide-ranging marine predator, the Steller sea lion Eumetopias jubatus. We used these hypotheses to develop a series of habitat models predicting the probability of sea lions occurring within a $3 \times 3 \mathrm{~km}^{2}$ grid in the Gulf of Alaska and the Bering Sea. We compared these deductive model predictions with opportunistic at-sea observations of sea lions (presence-only data) using (1) a likelihood approach in a small area where effort was assumed to be uniformly distributed and (2) an adjusted skewness ( $\left.\mathrm{Sk}_{\mathrm{adj}}\right)$ test that evaluated the distribution of the predicted values associated with true presence observations. We found that the $\mathrm{Sk}_{\text {adj }}$ statistic was comparable to the likelihood test when using pseudo-absence data, but it was more powerful for assessing the relative performance of the different predictive spatial models across the entire study area. The habitat maps we produced for adult female sea lions using the deductive modelling approach captured a higher proportion of presence observations than the current habitat model (critical habitat) used by fisheries managers since 1993 to manage Steller sea lions. Such improved predictions of habitat are necessary to effectively design, implement and evaluate fishery mitigation measures. The deductive approach we propose is suitable for modelling the habitat use of other age and sex classes, and for integrating these age/sex-class-specific models into a revised definition of critical habitat for Steller sea lions. The skewness test provides a means of comparing the relative performance of such models, using presence-only data. The approach can be readily applied to other central-place foragers.
\end{abstract}

KEY WORDS: Steller sea lion - Critical habitat - Endangered species - Ecosystem management Habitat model $\cdot$ Skewness $\cdot$ Bering Sea $\cdot$ Gulf of Alaska

\section{INTRODUCTION}

Designating critical habitat for endangered marine species is required under the United States Endangered Species Act (1972). However, there are no guidelines or methods available to assist in this task. In the case of Steller sea lions Eumetopias jubatus, critical habitat for the endangered western population was determined in 1993 to include all major terrestrial resting sites (rookeries and haulouts) and their associated aquatic zones, extending 20 nautical miles $(37 \mathrm{~km})$ seaward, plus several putative sea lion foraging areas in the Bering Sea
(Fig. 1; U.S. Federal Register 50 CFR 226.202). This designation of Steller sea lion critical habitat has formed the basis of all subsequent protection legislation, despite no formal statement outlining and justifying the rationale for the boundaries.

Most marine mammals are broadly distributed and infrequently surveyed, typically over only portions of their ranges. Habitat used by marine mammals can be inferred from direct counts of animals observed along line-transects, or from animals equipped with satellite-linked tracking tags (e.g. Bradshaw et al. 2004, Ciannelli et al. 2004, Matthiopoulos et al. 2004). 


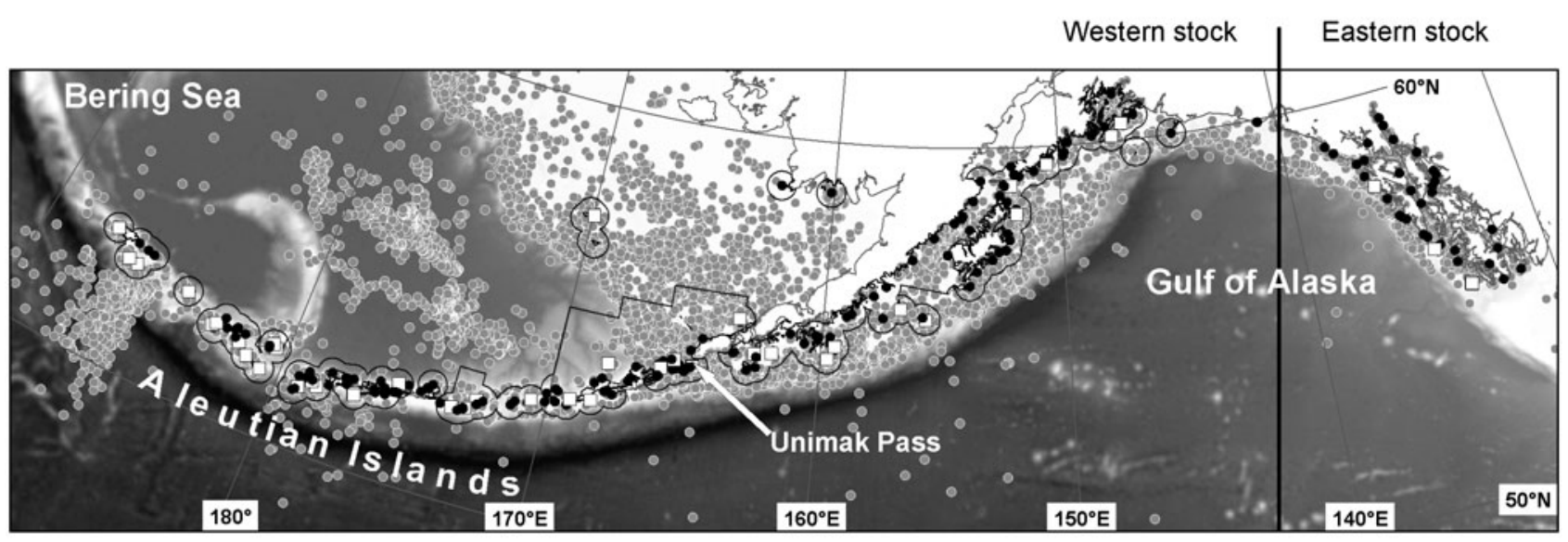

Fig. 1. Study area showing the spatial extents of the study. $\square$ : Major Steller sea lion Eumetopias jubatus breeding sites (rookeries); •: other major terrestrial sites. •: Platform of opportunity (POP) sightings of Steller sea lions. Critical habitat is shown as a black line, and the coastline is in grey. The marine portion is shaded from light to dark in increasing depth. Model performance was tested for the western stock only

These studies have been effective primarily because the extent of the telemetry data matched the foraging range of the species under investigation. However, telemetry data on Steller sea lions have been collected at only a few sites and for a relatively small number of juveniles and adult females, and provides an incomplete picture of seasonal changes in distribution because tag deployment and duration of attachment is influenced by the timing of moult (Raum-Suryan et al. 2004, Pitcher et al. 2005). Given the evidence of site and season-specific foraging (Loughlin et al. 1998, Raum-Suryan et al. 2002, Gende \& Sigler 2006), ecological signals relevant to identifying sea lion habitat may be obscured if telemetry data are combined from different sites or generalized from a single season. Consequently, combined telemetry data may not be suited to developing seasonal, range-wide habitat models for such a wide-ranging species.

In the absence of census data with broad temporal and spatial distributions, there is little practical use in seeking correlations to establish species-habitat relationships (e.g. Guisan \& Zimmerman 2000). Additionally, correlative analyses generally do not identify the ecological mechanisms that underlie the correlations and are essential to understanding the ecology of the species (i.e. how the correlates influence species distributions). Simply extrapolating correlations to infer spatial and temporal habitat use may be problematic if the mechanisms are not understood, particularly under changing environmental conditions (Guisan \& Zimmerman 2000).

An alternative to the correlative approach is to use deduction - a logical method to identify specific consequences stemming from a known set of facts. This approach, termed environmental envelope modelling, is the simplest way to represent large-scale relationships between animal distributions and physical descriptions of habitat (Redfern et al. 2006). Kaschner et al. (2006) successfully used this approach to identify the global ranges of 115 species of pinnipeds and cetaceans. We built upon this general approach by focusing on a single species (Steller sea lions), at a higher spatial resolution, and over smaller spatial extents than previously considered.

Our study had 3 main goals. We first wanted to demonstrate how deductive models can be developed in the absence of biological sampling data. Using published information on diet, species life history, regional oceanography, and past and present terrestrial distributions, we applied an increasingly complex set of hypotheses to identify sea lion habitat based on general ecological principles. This approach allows relevant available information to be included in the habitat definition, provided a suitable a priori hypothesis (i.e. ecological mechanism) can be formulated. Our second goal was to evaluate the performance of the resulting habitat models with opportunistic observations of sea lions at sea (presence-only data) across the entire species' range. We did so by developing a diagnostic tool that evaluates model performance based on the skewness (a measure of asymmetry) of the model predictions associated with the presence observations. Finally, we compared our model predictions to the currently designated critical habitat and showed that our deductive models captured a larger proportion of at-sea sea lion observations. This demonstrates that a more defensible model of critical habitat can be developed than the one currently in use for Steller sea lions in Alaska.

\section{MATERIALS AND METHODS}

Our study area extended from southeast Alaska to the end of the Aleutian Island chain (Fig. 1) between 50 and $65^{\circ} \mathrm{N}$ latitude and $130^{\circ} \mathrm{W}$ and $170^{\circ} \mathrm{E}$ longitude. 
We overlaid this region with a $3 \times 3 \mathrm{~km}^{2}$ grid, which reflected the limit of the bathymetric resolution. Given that Steller sea lions engage in foraging trips of 10 s to 100 s of $\mathrm{km}$, we felt that this resolution was reasonable for examining the relative habitat suitability across the range of the species. We selected the major terrestrial sites used by Steller sea lions - defined as sites where the annual count exceeded 75 animals in winter or 200 animals in summer, at least once since 1979 (Kruse et al. 2001) - using the database of Steller sea lion counts maintained by the United States National Marine Fisheries Service (NMFS; NMML 2006a,b). These terrestrial sites served as the central places from which we assumed Steller sea lions foraged. Positional data on these sites were obtained from the National Marine Mammal Laboratory, NMFS (NMML unpubl. data). The locations of these sites and the platform of opportunity (POP) presence-only sea lion sightings (used for model validation) were obtained as latitudelongitude coordinates. We projected these data onto an equal-area map representation using the Alaska Albers Conic projection (Fig. 1).

We standardized the display of our predicted habitat suitability across all of our models. We shaded each grid cell in the study area from black (lowest probability), through blue to green (intermediate probability), and finally yellow to red (highest probability). Land and areas of zero probability were shown in white.

Model hypotheses. We divided our model-building hypotheses into the 2 independent concepts of accessibility and suitability of the marine environment for foraging Steller sea lions (Table 1). Our accessibility hypotheses were based on published age- and sexspecific constraints, while our suitability hypotheses described how different marine regions compared according to their foraging suitability. With the exception of the habitat suitability components, we did not compare the predictive performance of the various hypotheses (Table 1 ) because the deductive approach assumes the resulting predictions are the consequences (i.e. deductions) of what is believed to be true. Thus, while the relative performance of different species-habitat hypotheses can be assessed as part of this approach, our intent was to define a number of acceptable hypotheses a priori, based on the ecology of the species.

We modelled our predicted probabilities $\left(\operatorname{Pr}_{j}\right)$ as a continuous variable on the range $[0,1]$ for each location $j$. The probabilities were calculated as the joint probability (i.e. product) of accessibility and suitability, after standardizing each onto the range $[0,1]$. In cases were suitability was a function of several variables (e.g. $S_{1}, S_{2}, \ldots S_{N}$ ), the variables were standardized and then averaged as follows:

$$
\operatorname{Pr}_{j}=\text { Accessibility }_{j} \times \frac{1}{N}\left(S_{1, j}+S_{2, j}+\ldots+S_{N, j}\right)
$$

This definition ensured that an area was both accessible and suitable in order to represent habitat for the species, a necessary condition before any conclusions about habit preferences can be drawn (Matthiopoulos et al. 2004). Suitability also served to differentiate between regions of equal accessibility.

Accessibility: As central-place foragers, Steller sea lions regularly rest on land between foraging trips (Merrick \& Loughlin 1997, Brandon 2000, Trites \& Porter 2002, Milette \& Trites 2003). We therefore began with the hypothesis that the at-sea distribution of Steller sea lions is related to the accessibility of the marine environment from the central place (Hypothesis 1; Table 1). We calculated the at-sea distance from each major terrestrial site to each $3 \times 3 \mathrm{~km}^{2}$ cell in the study area using a cost-distance function (Eastman 2001), while accounting for land barriers. We used the positive half of a normal curve (Fig. 2a) to relate the probability of sea lion occurrence to marine accessibility. We chose this representation because foraging animals are constantly moving, implying no additional energetic cost to foraging some distance away from the site rather than directly adjacent to it. This effectively means that, within a certain range of the central place, there is little difference in accessibility, though accessibility drops rapidly beyond this range (Hypothesis 2; Table 1).

Telemetry studies have demonstrated a significant seasonal difference in the distances travelled by adult females during the breeding (summer) and non-breeding (winter) seasons (Merrick \& Loughlin 1997), indicating the need for a seasonal accessibility model at least for adult females (Hypothesis 3; Table 1). We calibrated the accessibility curves for adult females (Fig. 2a) by making the standard deviations equal to the reported mean seasonal distance travelled (summer mean $=10 \mathrm{~km}$, winter mean = $133 \mathrm{~km}$; Merrick \& Loughlin 1997). We defined the summer breeding season as May to August and the non-breeding season as September to April, a time when all animals of both sexes tend to be distributed across a wider range (Loughlin et al. 1987, Merrick \& Loughlin 1997, Trites \& Porter 2002). We focused our analysis on adult females during the winter because their summer distribution was too constrained to support further analysis at the spatial resolution of our study.

Suitability: We investigated several definitions of habitat suitability based on the assumption that the distribution of foraging adult female sea lions is in some way related to population counts and the physical environment. We first hypothesized that animal abundance could serve as a proxy for habitat suit- 
ability and developed a population-based suitability model, based on the assumption that terrestrial sites with larger populations are surrounded by more, higher quality habitat than sites with fewer animals (Hypothesis 4; Table 1). Given their high degree of natal site fidelity (Raum-Suryan et al. 2002) and telemetry data showing central-place foraging (Merrick \& Loughlin 1997, Loughlin et al. 1998), it is reasonable to hypothesize that the population at a site is proportional to the at-sea food resources available, assuming most foraging occurs from the central place (rather than during movement between sites).
We implemented this central-place foraging hypothesis by weighting the different terrestrial sites according to their proportion of the total population. We averaged the non-zero adult counts from the entire record (NMML 2006a) at each site during the winter and summed these to get a total non-breeding season count for the entire range. We then summed the weighted suitability surfaces for all sites to generate the final, population-based suitability prediction. While this approach distinguished the relative site suitability, it did not distinguish between areas at the same distance from a particular site.

Table 1. Eumetopias jubatus. Hypotheses used to develop the predictive habitat models. Accessibility hypotheses form the basis of the model and the rationale for seasonal and age-based components. Suitability assumptions are additive and serve to distinguish between equally accessible regions. Accessibility and suitability are considered independent. SSL: Steller sea lion

\begin{tabular}{|c|c|}
\hline Hypothesis & Ecological basis \\
\hline $\begin{array}{l}\text { Habitat accessibility } \\
\text { 1. SSL at-sea distributions are related to the accessibility } \\
\text { of the marine environment from the central place. }\end{array}$ & $\begin{array}{l}\text { - SSL are not randomly distributed in the ocean. } \\
\text { - Steller sea lions regularly rest on land between foraging } \\
\text { trips (Merrick \& Loughlin 1997, Brandon 2000, Trites \& } \\
\text { Porter 2002, Milette \& Trites 2003). }\end{array}$ \\
\hline $\begin{array}{l}\text { 2. Marine areas within a certain radius of a site are } \\
\text { similarly accessible. }\end{array}$ & $\begin{array}{l}\text { - Foraging implies constant movement. This implies no } \\
\text { additional cost to foraging some distance away from the site } \\
\text { compared to directly adjacent to it. }\end{array}$ \\
\hline $\begin{array}{l}\text { 3. o SSL display a significantly different distribution } \\
\text { during the breeding and non-breeding seasons. This } \\
\text { requires a seasonal model, at least for adult females. }\end{array}$ & $\begin{array}{l}\text { - Most } q \text { SSL are constrained to rookeries during breeding. } \\
\text { - Significant seasonal differences in the distance travelled by } \\
\text { adult females during the breeding and non-breeding } \\
\text { seasons (Merrick \& Loughlin 1997). }\end{array}$ \\
\hline $\begin{array}{l}\text { Habitat suitability } \\
\text { 4. Average, long-term counts of SSLs provide a measure of } \\
\text { the relative suitability of the marine environment } \\
\text { around the site. Occupancy of a terrestrial site is } \\
\text { proportional to the available at-sea resources. }\end{array}$ & $\begin{array}{l}\text { - Most adult o SSLs return to natal rookeries (Raum-Suryan } \\
\text { et al. 2002). } \\
\text { - Foraging behaviour is site specific (Loughlin et al. 1998). } \\
\text { - Steller sea lions regularly rest on land between foraging } \\
\text { trips (Merrick \& Loughlin 1997, Brandon 2000, Trites \& } \\
\text { Porter 2002, Milette \& Trites 2003). }\end{array}$ \\
\hline $\begin{array}{l}\text { 5. At-sea SSL habitat can be related to physical oceano- } \\
\text { graphy. Marine habitat is related to prey availability } \\
\text { and abundance. Fish distributions can be generalized } \\
\text { using a few simple relationships. }\end{array}$ & $\begin{array}{l}\text { Diet diversity (Sinclair \& Zeppelin 2002, Trites et al. 2007) } \\
\text { suggests sea lions likely forage on what is most catchable } \\
\text { in the vicinity of a terrestrial site. }\end{array}$ \\
\hline $\begin{array}{l}\text { 5a. Sea lion foraging opportunities are maximized near } \\
\text { the } 200 \mathrm{~m} \text { contour. }\end{array}$ & $\begin{array}{l}\text { - Maximum densities of both benthic and pelagic fish are } \\
\text { consistently reported around the } 200 \text { m contour (NOAA } \\
\text { 1990, Wolotira et al. 1993). }\end{array}$ \\
\hline $\begin{array}{l}\text { 5b. Bottom slope is a reasonable index of habitat suit- } \\
\text { ability for SSL prey. }\end{array}$ & $\begin{array}{l}\text { - High slope areas (e.g. the shelf break, canyons, sea mounts) } \\
\text { are often associated with high marine productivity primar- } \\
\text { ily because of their interaction with water flow (Bakun } \\
\text { 1996). } \\
\text { - Adults of many benthic species are concentrated near steep } \\
\text { areas around submarine canyons and on the continental } \\
\text { slope (NOAA 1990, Wolotira et al. 1993). }\end{array}$ \\
\hline $\begin{array}{l}\text { 5c. Variability in sea surface height is a reasonable } \\
\text { index of SSL prey abundance. }\end{array}$ & $\begin{array}{l}\text { - Oceanographic frontal activity is positively correlated with } \\
\text { features that concentrate prey (i.e. zooplankton) for SSL } \\
\text { prey species. }\end{array}$ \\
\hline
\end{tabular}


To capture some of the environmental heterogeneity, we developed suitability models using physical oceanographic variables. While Merrick \& Loughlin (1997) concluded that female foraging is only constrained by reproductive status and changes in prey availability, Loughlin et al. (1998) showed that individuals from different sites exhibited significantly different foraging patterns within the same season, presumably because habitat characteristics differed between sites. We hypothesized that these habitat characteristics could be distinguished using physical oceanographic data (Hypothesis 5; Table 1).

At-sea habitat suitability for Steller sea lions can be assumed to be largely determined by prey abundance and accessibility. Given the diversity of their diet (Sinclair \& Zeppelin 2002, Trites et al. 2007), sea lions likely forage on what is most catchable (within their list of preferred prey species) in the vicinity of a terrestrial site. We therefore chose 2 variables that appear to have some ecological significance for the distribution of prey sought by sea lions - slope and the $200 \mathrm{~m}$ contour.

Considerable evidence points to the ecological importance of the $200 \mathrm{~m}$ contour. The depth distribution of demersal fishes in the Aleutians ranges from 100 to $400 \mathrm{~m}$ (Logerwell et al. 2005), and maximum densities of both benthic and pelagic fish are consistently reported around $200 \mathrm{~m}$ depth (NOAA 1990, Wolotira et al. 1993). Essential fish habitat descriptions for many species associate them with the shelf edge (NMFS 2005), also characterized by about $200 \mathrm{~m}$ depth. Since $200 \mathrm{~m}$ is well within the diving range of Steller sea lions and fish often move towards the surface at night to feed, the potentially high number of pelagic and benthic fish species in waters associated with this depth could provide higher than average encounter rates and prey diversity (Hypothesis 5a; Table 1). We therefore defined sea lion habitat suitability using a trapezoidal distribution with the highest suitability (1.0) between 150 and $250 \mathrm{~m}$. We linearly decreased the suitability outside this range to 0 at $2500 \mathrm{~m}$ depth and to 0.5 at $5 \mathrm{~m}$ depth (Fig. 2b), to recognize that foraging opportunities exist both further from shore and in shallower waters.

High slope areas (e.g. the shelf break, canyons, sea mounts) are often associated with high marine productivity, primarily because of their interaction with water flow (Bakun 1996). Schooling pelagic species often tend to shoal at the continental shelf edge, or in other regions of steep slope (e.g. walleye pollock; Smith 1981), while the adults of many benthic species are concentrated near steep areas around submarine canyons and on the continental slope (NOAA 1990, Wolotira et al. 1993). We therefore assumed that sea lion habitat suitability increased linearly with increasing slope (Hypothesis 5b; Table 1, Fig. 2c).
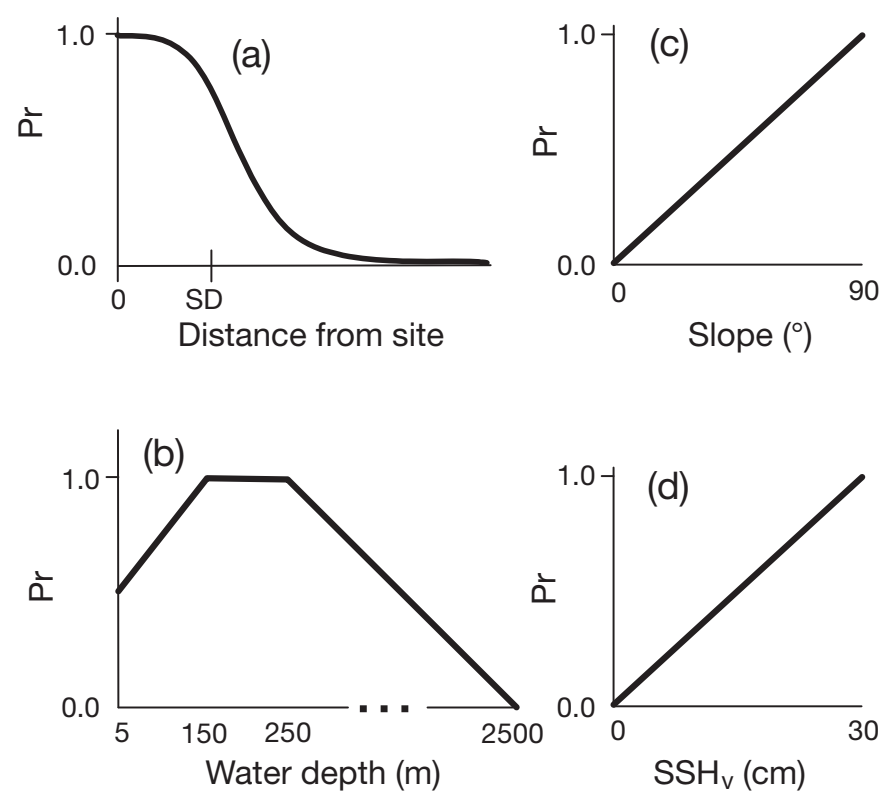

Fig. 2. Eumetopias jubatus. Likelihood curves used to translate physical variables to habitat suitability $(\mathrm{Pr})$ for Steller sea lions. (a) Distance from terrestrial sites formed the basis of the accessibility model and was represented as the positive half of a normal curve, where the standard deviation (SD) was set to the mean distance travelled during the breeding (summer = $17 \mathrm{~km}$ ) and non-breeding (winter $=133 \mathrm{~km}$ ) seasons (Merrick \& Loughlin 1997). (b) Water depth shows the influence of bathymetry, assuming optimum foraging occurs at depths between 150 and $250 \mathrm{~m}$. Habitat suitability was hypothesized to increase (c) linearly with slope and (d) sea surface height variability $\left(\mathrm{SSH}_{\mathrm{v}}\right)$. Depth, slope and $\mathrm{SSH}_{\mathrm{v}}$ were components of the habitat suitability models

We also wanted to include some measure of habitat suitability related to environmental variability, in addition to the invariant measures related to bathymetry (depth and slope). Fronts have been significantly correlated with at-sea locations of pinnipeds (e.g. Guinet et al. 2001, Lea \& Dubroca 2003). We thus hypothesized that areas of consistent frontal activity, as measured by high variability in sea surface height $\left(\mathrm{SSH}_{\mathrm{v}}\right)$, could provide increased foraging opportunities for sea lions by attracting fish to these productive oceanographic features (Hypotheses 5c; Table 1). We represented sea lion habitat suitability as linearly increasing with $\mathrm{SSH}_{\mathrm{v}}$ (Fig. 2d).

We developed maps of depth and slope using the Smith \& Sandwell (1997) global bathymetric coverage, which has an approximate spatial resolution of $2 \mathrm{~min}$. We calculated the average depth and slope (steepness) for each $9 \mathrm{~km}^{2}$ grid cell using IDRISI software (Eastman 2001). Slope was calculated in degrees (range = 0 to 90 ) for each cell according to the elevation difference between its neighbours. $\mathrm{SSH}_{\mathrm{v}}$ was calculated using images of weekly sea level anomalies from 1993 to 2003 , obtained at a resolution of $1 / 3^{\circ} \times 1 / 3^{\circ}$ from an 
online server (AVISO 2005). After projecting the weekly data onto $20 \times 20 \mathrm{~km}^{2}$ grids, we calculated the variability in sea surface height as the variance across all weeks of the winter season in all years using ArcGIS (ESRI 2005). We re-sampled the result onto our $9 \mathrm{~km}^{2}$ study grid.

Model development. We began by building a model of winter accessibility (WA). Combining this accessibility model with the count data created a simple, populationbased habitat suitability (PS) model. We then examined how well each habitat suitability variable (depth, slope and $\mathrm{SSH}_{\mathrm{v}}$ ) predicted the POP observations when combined with WA. Finally, we created 2 habitat suitability (HS) models using: (1) the combination of the 2 habitat suitability variables with the most negative skewness scores (HS1: depth and $\mathrm{SSH}_{\mathrm{v}}$ ), and (2) the combination of all 3 habitat suitability variables (HS2: depth, $\mathrm{SSH}_{\mathrm{v}}$ and slope). This resulted in 4 different habitat descriptions (WA, PS, HS1 and HS2) that we compared to each other and to the critical habitat $(\mathrm{CH})$ model currently used for management.

Model performance. The best way to validate predictions of habitat is to compare them with observations of presence and absence from animal distributions surveys. However, the only range-wide distributional data for Steller sea lions are the POP data maintained by the NMFS (S. Mizroch pers. comm.). Although the POP sightings provide an unequivocal indication of species presence, no information on observational effort means that the data cannot be considered to be an unbiased, representative sample of the species' true distribution. This means that neither presence-only modelling methods (e.g. Hirzel et al. 2002), nor the commonly used measures of model performance such as Kappa statistics or receiver-operator characteristics plots (e.g. Fielding \& Bell 1997) are appropriate for these data. We propose that a skewness test is a more appropriate means of comparing the POP data with the model results.

Skewness is the third standardized moment about the mean, and is a measure of the symmetry of a distribution (Zar 1996). The more negatively skewed a distribution is (long left-hand tail), the higher proportion of positive values it will have. Better performing predictive models should show an increased overlap between high predictions and true presence values, resulting in increasingly negative skewness. The approach thus uses the POP data for validation, rather than for the development of a correlative model-arguably a more suitable use for opportunistically collected data.

We evaluated the skewness test by comparing how it ranked the different models, compared to a simple likelihood approach using the sum of squares. This more conventional model performance statistic requires both presence and absence data. Without true absence data, a common approach is to define pseudoabsence values by assuming equal effort across all or a portion of the study area (e.g. Gregr \& Trites 2001). Since the majority of the POP data were collected from fishing vessels, we defined such a spatial subset using the kernel density (Beyer 2004) of the observed trawl fishing effort from the NMFS fisheries observer database (Fig. 3). We selected enough of the highest density region (33\% by volume of the kernel density) such that the range of predicted values in the selected space spanned from 0 to 1 . This defined the spatial subset with assumed equal effort we used to compare the 2 model performance measures (sum of squares and skewness).

We used a corrected sum of squares statistic proposed by Hilborn \& Mangel (1997) to rank the models according to how their predictions differed least from the observed number of presence and pseudo-absence cells:

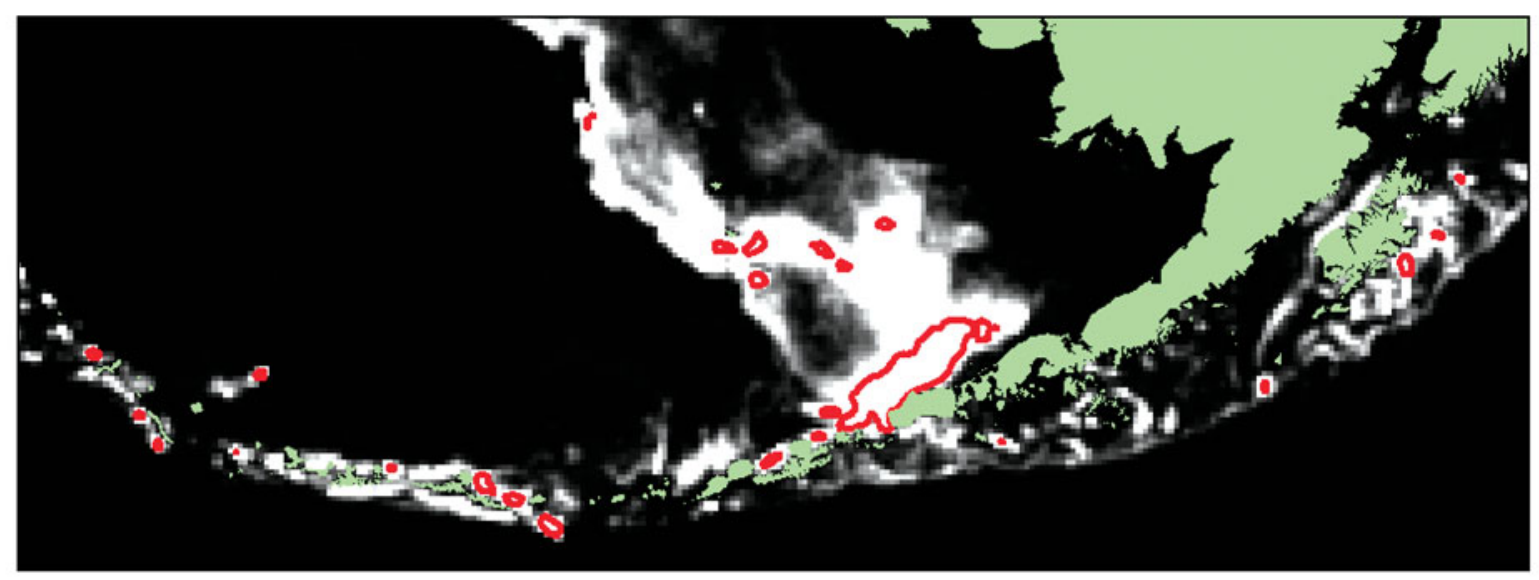

Fig. 3. Eumetopias jubatus. Spatial subset (red) representing the $33 \%$ volume contour of the density kernel of all observed trawl effort (from the NMFS observer database) between 1976 and 2005 


$$
\mathrm{SS}_{m}=\frac{\sum_{N_{P}}(1-\text { presence })^{2}+\sum_{1-N_{P}}(\text { absence })^{2}}{N-2 p_{m}}
$$

where $\mathrm{SS}_{m}$ is the sum of squares statistic for model $\mathrm{m}$, presence is the set of $N_{p}$ POP-associated predictions, absence is the number of empty cells remaining in the spatial subset (the pseudo-absences), $N$ is the sample size, and $p_{m}$ is the number of parameters in model $\mathrm{m}$.

Our skewness statistic $\left(\mathrm{Sk}_{\mathrm{adj}}\right)$ is based on the predicted probabilities associated with the POP sightings. Models generating a more negatively skewed distribution of POP-associated probabilities were deemed to perform better than those with a more positive skewness. However, the predicted values associated with POP sightings are a function of both the spatial distribution of the predictions (the desired performance measure) and their relative abundance over the entire model space. We corrected for the bias due to the abundance of the different predictions by multiplying the POP-associated predictions by the ratio of total probabilities across the entire model space to the number in each distribution class. We defined our performance statistic, adjusted skewness $\left(\mathrm{Sk}_{\mathrm{adj}}\right)$, as the skewness of this weighted distribution:

$$
C_{\text {pres }, i}^{\prime}=C_{\text {pres }, i} \times \frac{\sum_{i=1}^{100} C_{\text {total }, i}}{C_{\text {total }, i}}
$$

where $C_{\text {pres }, i}^{\prime}$ is the weighted count of true presences for each distribution class $i(i=1, \ldots, 100), C_{\mathrm{pres}, i}$ is the unweighted count, and $C_{\text {total }, i}$ is the total number of grid cells in each class. We assessed all distributions using 100 classes.

We calculated $\mathrm{Sk}_{\mathrm{adj}}$ for the POP observations in both the spatial subset (Fig. 3) and the range-wide study area (Fig. 1). We compared the performance of $\mathrm{Sk}_{\mathrm{adj}}$ with the likelihood statistic $\mathrm{SS}_{m}$ for the spatial subset only.

Finally, we examined whether our predictive models performed better than the currently designated $\mathrm{CH}$. To partition our modelled probabilities into binary presence/absence models (because the designated $\mathrm{CH}$ model is presence/absence), we selected the highest probability grid cells from each model such that the resulting binary models contained the same amount of habitat (in terms of number of grid cells) as the $\mathrm{CH}$ model. The designated $\mathrm{CH}$ model contained a total of 38710 grid cells of ocean habitat (approximately $350000 \mathrm{~km}^{2}$ ). We examined what proportion of the POP data fell within our modelled $\mathrm{CH}$, and compared proportions with the designated $\mathrm{CH}$ using a chi-squared test for differences in proportion.

\section{RESULTS}

\section{Model development}

The suitability predictions of the individual habitat variables depth, slope and $\mathrm{SSH}_{\mathrm{v}}$ showed obvious differences in how they distributed habitat suitability in space (Fig. 4) and across the POP observations (Fig. 5). The $\mathrm{SSH}_{\mathrm{v}}$ habitat variable ranked best (most negative) with $\mathrm{Sk}_{\mathrm{adj}}=-0.66$, followed by depth with $\mathrm{Sk}_{\mathrm{adj}}=$ -0.62 . Slope performed the worst with $\mathrm{Sk}_{\mathrm{adj}}=0.12$.

Depth suitability included a significant portion of the southeast Bering Sea and Gulf of Alaska shelf, while slope suitability was predominantly along the shelf edge and the Aleutian Islands, where there is considerable topographic variability. $\mathrm{SSH}_{\mathrm{v}}$ showed an interesting pattern of suitability patches both near shore (particularly in the Gulf of Alaska) and away from shore along the Aleutian Islands. Depth-based predictions of suitability were the most spatially concentrated and had a large proportion of high probabilities, while $\mathrm{SSH}_{\mathrm{v}}$ suitability had fewer high-probability areas, but showed more broadly distributed moderate probabilities.

We identified 222 major terrestrial sites for Steller sea lions in the NMFS count database. These formed the basis of the accessibility component of our models (Fig. 1; 52 rookery sites and 170 haulout sites). Predictions of the WA model (Fig. 6a) reflect the 2 basic assumptions about central-place foraging and the mean winter distance travelled from shore. The predictions from the PS model for adult females in winter (Fig. 6b) showed how including long-term average counts resulted in 2 concentrations of high predicted suitability, one in the Aleutian Islands and the other at the western end of the Alaskan Peninsula.

We formulated the HS models according to the $\mathrm{Sk}_{\text {adj }}$ scores of the habitat variables. We defined HS1 to include the 2 habitat variables with the best $\mathrm{Sk}_{\mathrm{adj}}$ scores (depth and $\mathrm{SSH}_{\mathrm{v}}$ ), and added the final variable (slope) to make HS2. HS1 (Fig. 6c) showed moderateto high-suitability habitat at locations on the Gulf of Alaska shelf, on the southeast Bering Sea shelf north of Unimak Pass and in the eastern Aleutian Islands. In contrast, the HS2 model (Fig. 6d) assigned these 3 regions only average suitability, assigned moderate suitability to areas further from shore (particularly in the Gulf of Alaska), and showed increased suitability in the western Aleutian Islands.

\section{Model performance}

The spatial subset (Fig. 3) consisted of 301 presence cells and 1707 pseudo-absences. It included a large area on the southeast Bering Sea shelf north of Unimak 


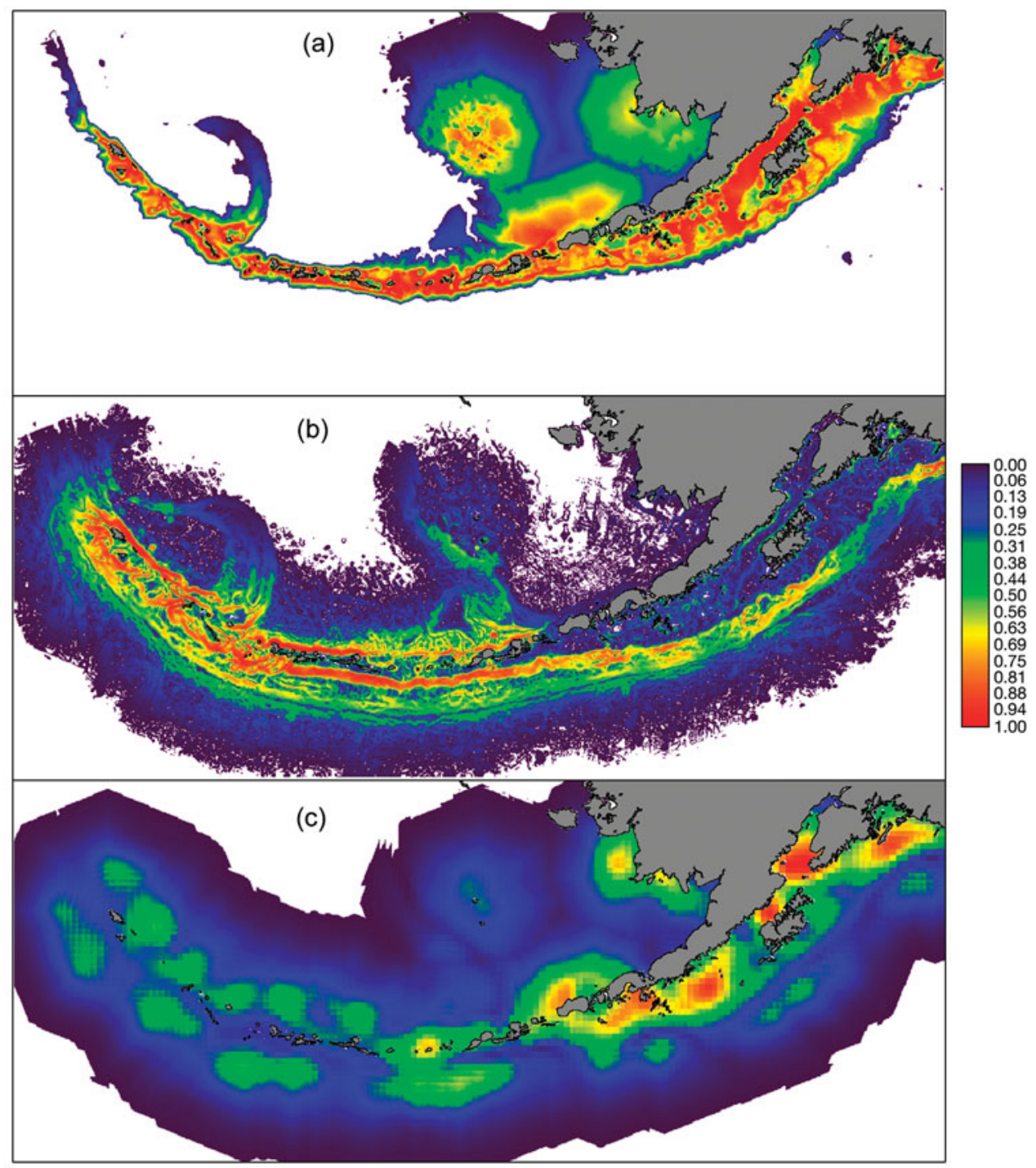

Fig. 4. Eumetopias jubatus. Habitat suitability predictions for adult female Steller sea lions during winter (non-breeding season), based on the individual habitat variables considered (a) depth, (b) slope and (c) sea surface height variability, each combined with winter accessibility. Model predictions of 0.0 are shown as white areas to clearly delimit the spatial extent of non-zero values
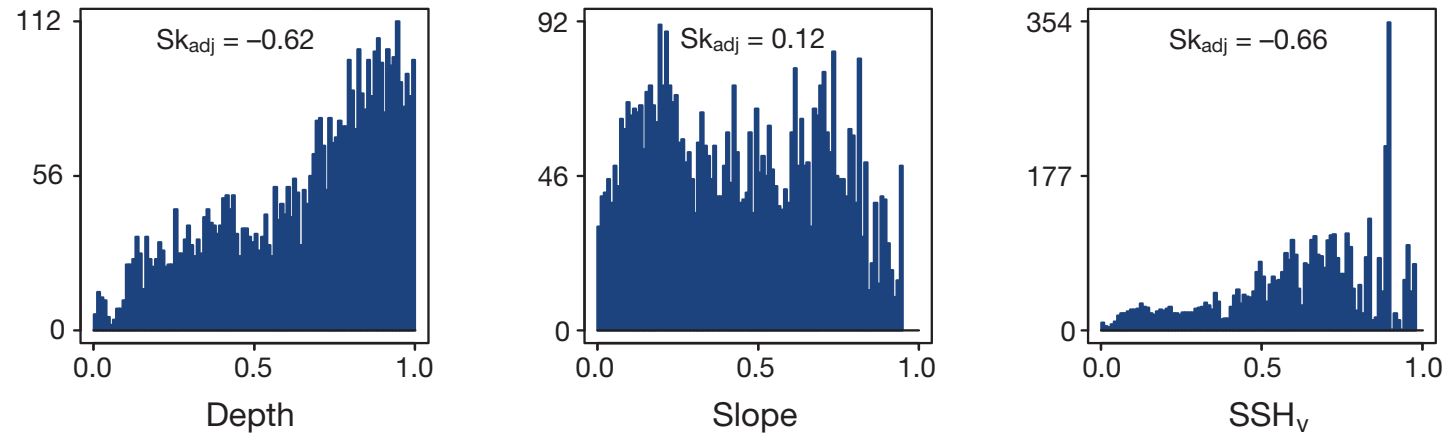

Fig. 5. Eumetopias jubatus. Adjusted distribution of POP-associated predictions for the 3 habitat model variables in the complete, range-wide study area. Adjusted skew $\left(\mathrm{Sk}_{\mathrm{adj}}\right)$ is shown 
Pass, and several small, on-shelf areas scattered throughout the study area. The sum of squares likelihood scores $\left(\mathrm{SS}_{m}\right)$ ranked the 4 models in order of increasing complexity, with HS2 achieving the lowest $\mathrm{SS}_{m}$, followed by HS1, PS and, finally, WA, with the highest $\mathrm{SS}_{m}$ (Table 2). The $\mathrm{Sk}_{\text {adj }}$ scores for the rangewide extents ranked the models in the same order, while the $\mathrm{Sk}_{\text {adj }}$ scores for the spatial subset showed the PS and HS2 models performing similarly, with the rank of the other 2 models unchanged. The distributions of model predictions across the study area (Fig. 7b) and of the weighted POP-associated predictions (Fig. 7c) show how the weighting affects the skewness. Model performance $\left(\mathrm{Sk}_{\mathrm{adj}}\right)$ is calculated from the weighted predictions.

Our assessment of how the 4 models performed against the currently designated $\mathrm{CH}$ required each of the 4 models to have a different threshold to capture the same area as contained in the currently designated $\mathrm{CH}$. The HS1 model had the highest threshold (0.338),

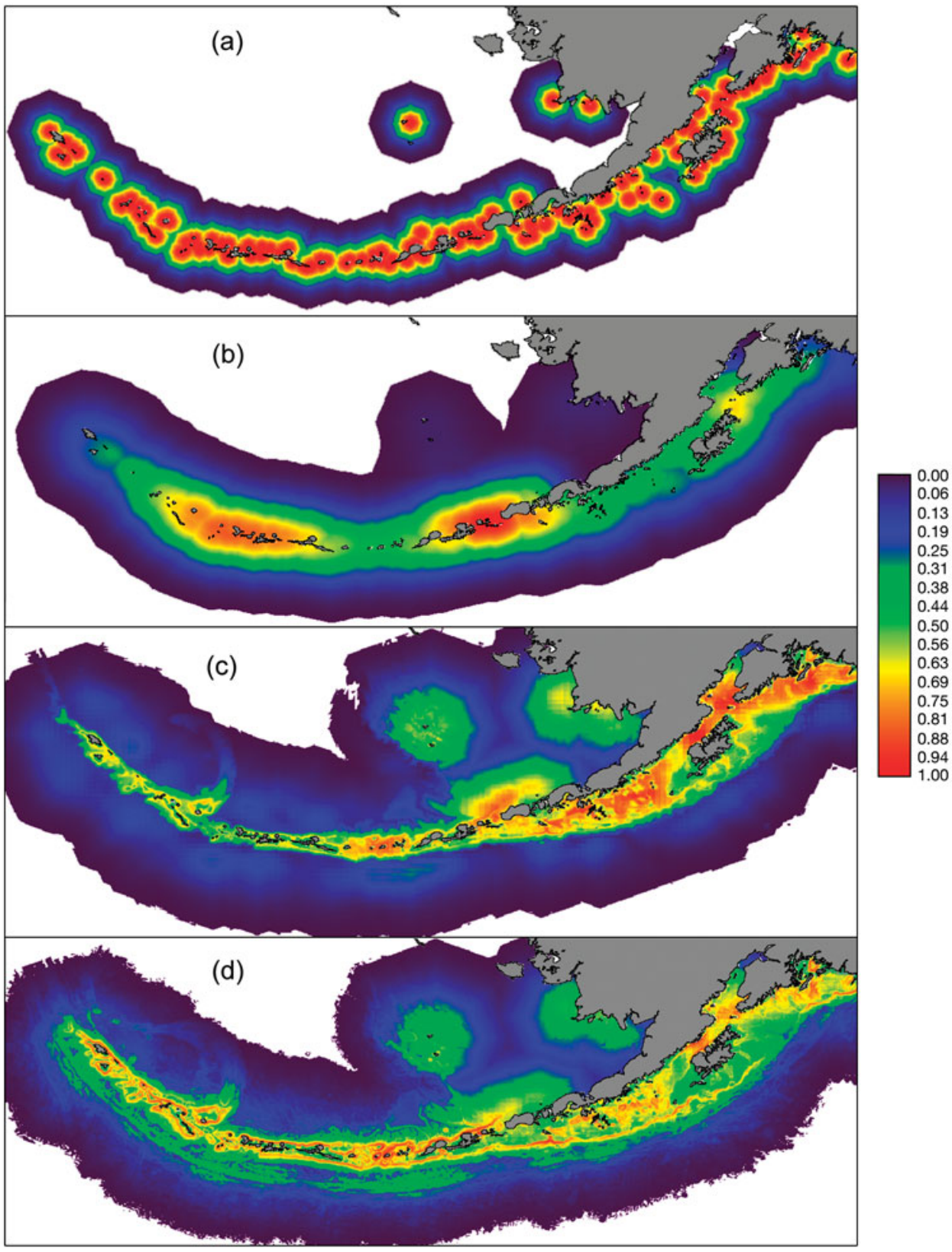

Fig. 6. Eumetopias jubatus. Habitat model predictions in order of increasing complexity for adult females during winter (non-breeding season): (a) accessibility, (b) population-based suitability, (c) habitat suitability 1 (depth and sea surface height variability) and (d) habitat suitability 2 (depth, sea surface height variability and slope). Model predictions of 0.0 are shown as white area to clearly delimit the spatial extent of non-zero values 
Table 2. Model performance scores for 4 habitat representations. A likelihood performance measure (sum of squares, SS) was calculated for a small subset (local spatial extents) of the modelled study area, where equal effort was assumed across all grid cells. Adjusted skew $\left(\mathrm{Sk}_{\mathrm{adj}}\right)$ is shown for both the local and the range-wide spatial extents. $\mathrm{SSH}_{\mathrm{v}}$ : variability in sea surface height

\begin{tabular}{|c|c|c|c|c|}
\hline \multirow[t]{2}{*}{ Model } & \multirow{2}{*}{$\begin{array}{l}\text { No. of } \\
\text { parameters }\end{array}$} & \multicolumn{2}{|c|}{ Local -} & \multirow{2}{*}{$\begin{array}{c}\text { Range-wide } \\
\mathrm{Sk}_{\mathrm{adj}}\end{array}$} \\
\hline & & SS & $\mathrm{Sk}_{\mathrm{adj}}$ & \\
\hline Winter accessibility & 1 & 0.719 & -0.230 & -0.476 \\
\hline Population-based suitability & 2 & 0.427 & -1.063 & -0.558 \\
\hline $\begin{array}{l}\text { Habitat suitability } 1 \\
\left(z, \mathrm{SSH}_{\mathrm{v}}\right)\end{array}$ & 7 & 0.353 & -0.257 & -0.786 \\
\hline $\begin{array}{l}\text { Habitat suitability } 2 \\
\left(z, \text { slope, } \mathrm{SSH}_{\mathrm{v}}\right)\end{array}$ & 9 & 0.253 & -0.923 & -0.885 \\
\hline
\end{tabular}

while the HS2 and WA models had the lowest (0.279). The proportion test showed significant differences for all pair-wise comparisons ( $\mathrm{p}<0.0001)$, except between the WA and PS models. Both HS models captured significantly more of the POP observations (HS1 $=43.7 \%$; $\mathrm{HS} 2=39.7 \%$ ) than the designated $\mathrm{CH}$ model $(36.1 \%)$, while the WA and PS models captured less (Fig. 8). Comparing the habitat contained within the $\mathrm{CH}$ and the HS1 models illustrates the relative differences between the 2 models and their relationship to the POP data (Fig. 9).

\section{DISCUSSION}

Many studies have described pinniped foraging behaviour (e.g. Merrick \& Loughlin 1997, McConnell et al. 1999, Bradshaw et al. 2004, Chilvers et al. 2005), but few have used the information gleaned from such studies to develop spatial predictions of pinniped distributions (e.g. Sjöberg \& Ball 2000, Matthiopoulos et al. 2004, Southwell et al. 2005), and only Kaschner et al. (2006) provided a general, range-wide prediction for Steller sea lions. The quantitative approach we took to describe fine-scale, at-sea distributions of Steller sea lions across their Alaskan range has not been previously attempted. Such range-wide habitat predictions are necessary to effectively design, implement and evaluate any measures intended to protect Steller sea lion populations.

The deductive approach to identifying Steller sea lion habitat we present demonstrates that species -habitat relationships can be defined for wide-ranging marine predators when data quality prevents the use of more common correlative approaches. Our models were derived from hypotheses about species behaviour and the behaviour of their prey (Table 1), and

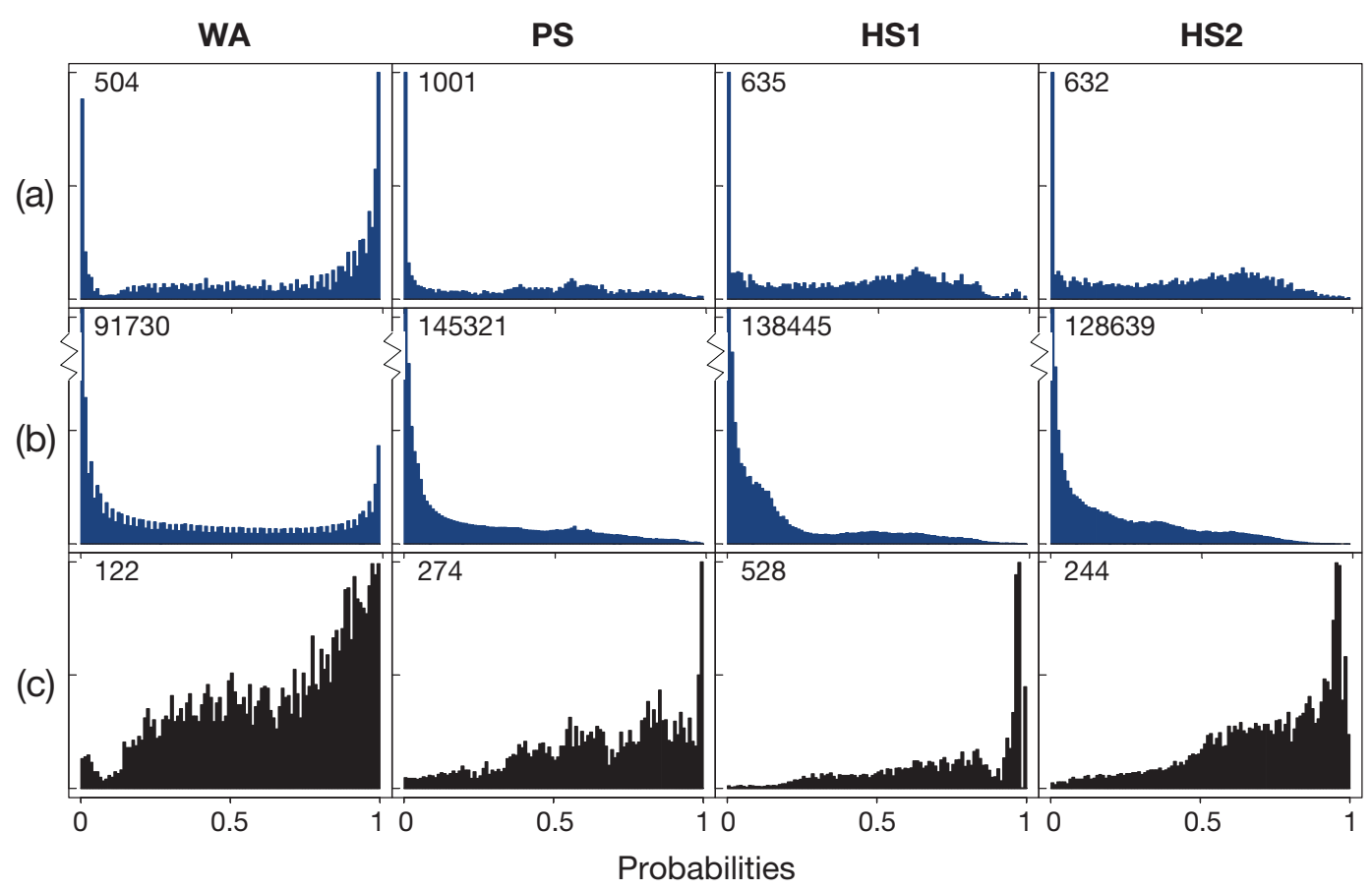

Fig. 7. Eumetopias jubatus. Distribution of (a) POP-associated predictions, (b) range-wide distribution of predictions for the entire model space and (c) adjusted distribution of POP-associated predictions, the basis of the adjusted skewness statistic (Sk $\left.\mathrm{adj}_{\mathrm{j}}\right)$. All $y$-axes are scaled from 0 to the maximum value shown, except in (b), where the maximum displayed is 30000 (true maximum is shown). The adjusted distribution of POP-associated predictions in (c) was obtained by weighting the distribution classes ( $\mathrm{n}=$ 100) by the ratio of the total model space (sum of all distributions) to the size of each distribution class (b), as predicted by each of the 4 models (WA: winter availability; PS: population-based habitat suitability; HS1: habitat suitability 1; HS2: habitat suitability 2) 


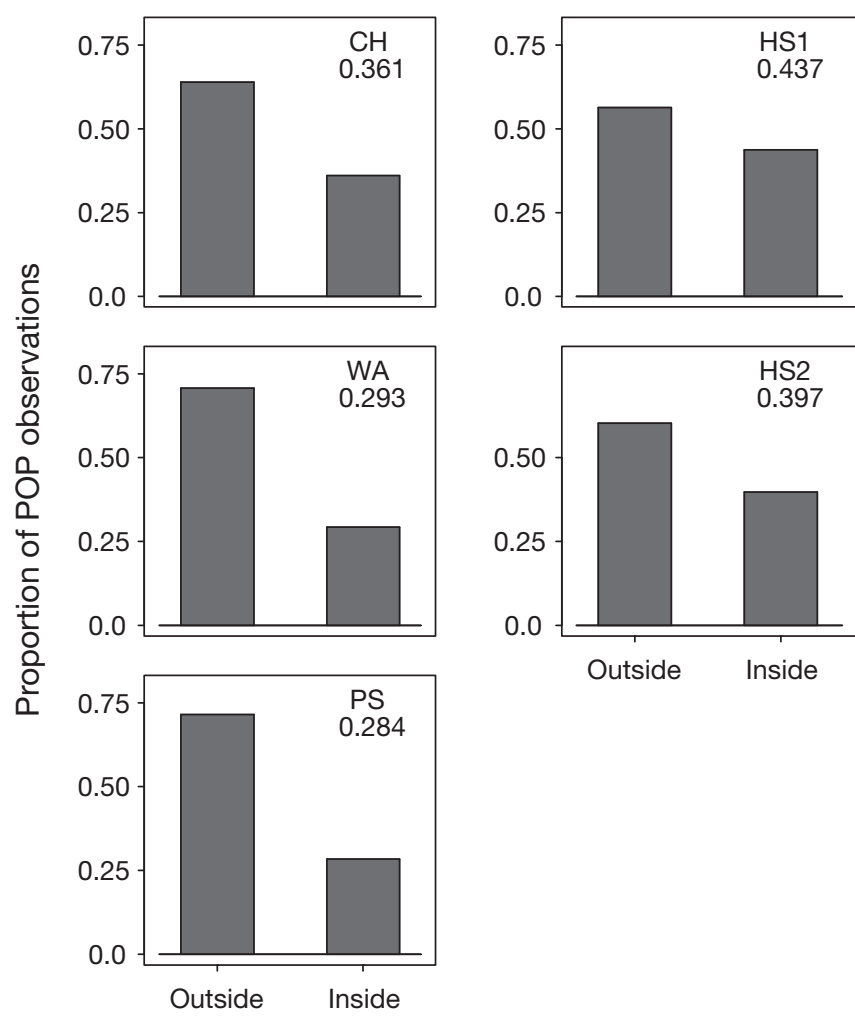

Fig. 8. Eumetopias jubatus. Proportion of POP observations that fell inside and outside the designated habitat for the 5 models. The proportions inside the boundary are shown and are significantly different for all pair-wise model comparisons except winter availability (WA) and populationbased habitat suitability (PS). $\mathrm{CH}$ : critical habitat; other abbreviations as in Fig. 7

resulted in fairly complex spatial predictions despite the relative simplicity of the core assumptions. This shows how simple hypotheses can lead to complex predictions, due to the spatial variability of the independent variables. Visualizing the spatial implications of habitat-use hypotheses has intrinsic value because it facilitates our understanding of how Steller sea lions may be related to their habitat.

\section{Model development}

The hypotheses we proposed to relate physical variables to the distribution of Steller sea lions were individually assessed and compared with opportunistic observations. Individually evaluating the habitat suitability hypotheses allowed the HS models to be developed iteratively, increasing complexity with the addition of each variable only if there was a significant increase in model performance. This is analogous to the recommended approach for models developed using correlative methods (Austin 2002).
Tests of model performance should reflect on the veracity of the underlying hypotheses. In this regard, the distribution of POP-associated depth suitabilities showed that sea lions were sighted with increasing frequency as the 150 to $200 \mathrm{~m}$ depths were approached (Fig. 5). This supported our hypothesis that this depth range is important to sea lions (although this could also reflect the distribution of vessels from which the observations were made). However, the available evidence does not appear to support our slope hypothesis. The weighted distribution $\left(C^{\prime}\right)$ appeared relatively uniform (Fig. 5), with the positive $\mathrm{Sk}_{\text {adj }}$ suggesting the POP observations were more frequent in areas of lower slope (contrary to our hypothesis). Thus, sea lion habitat appears to be unrelated to slope at the scale of our study $\left(3 \times 3 \mathrm{~km}^{2}\right)$. Similarly, bathymetric gradient was not significantly related to elephant seal distributions at a scale of $300 \times 300 \mathrm{~km}^{2}$ (Bradshaw et al. 2004). However, at higher resolutions, bottom topography has been shown to be significant for other marine species (e.g. Hui 1985, Southwell et al. 2005, Gregr et al. 2008). Therefore, the importance of slope may be positively correlated with increased spatial resolution. Thus, while our analysis was apparently too coarse to capture the habitat features implied by the slope hypothesis, we would expect slope to increase in significance at higher resolutions.

The POP observations associated with the hypothesized $\mathrm{SSH}_{\mathrm{v}}$ suitability showed a strong increase above a predicted probability of about 0.4 , leading to a high peak around 0.9. Fig. 4c shows that the relatively few areas with a $\mathrm{SSH}_{\mathrm{v}}$ probability $>0.50$ correspond with areas of high predicted depth suitability. The combined result (Fig. 6c) suggests that suitable depths may be distinguished in their habitat suitability according to the amount of local frontal activity. Thus, there appears to be some merit to our hypotheses about the significance of these physical features.

\section{Presence-only data and model validation}

We are aware of only 2 other approaches describing the use of presence-only data to evaluate model performance. Pearce \& Boyce (2006) described a crossvalidation approach that can be applied to abundance data. In our case, as with most marine mammal studies, cross-validation was unfeasible because at-sea abundance data are rarely available. Ottaviani et al. (2004) evaluated categorised model predictions by how well they overlapped with polygons of species presence. However, combining the POP observations into presence regions would have removed too much of the spatial variability that is likely important to sea lion 


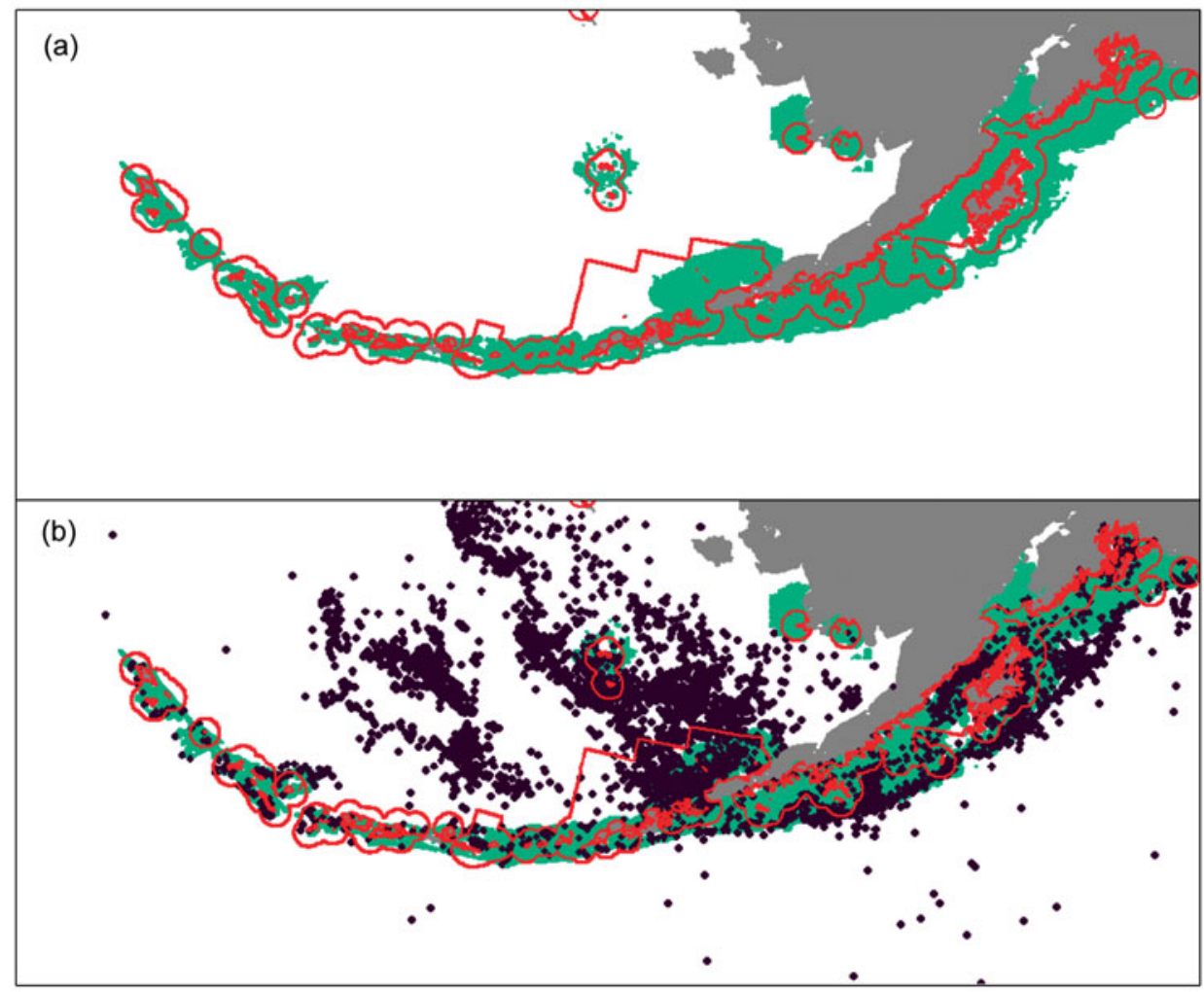

Fig. 9. Eumetopias jubatus. (a) Comparison of the designated critical habitat ( $\mathrm{CH}$, red outline) model for Steller sea lions to the predictive model (HS1, green shading) based on hypothesized depth and front $\left(\mathrm{SSH}_{\mathrm{v}}\right)$ suitability. The HS1 model captured $43.7 \%$ of the POP observations, while the designated $\mathrm{CH}$ model captured $36.1 \%$. The POP data are overlaid in (b) to support model comparisons

distributions. We therefore felt that a means of evaluating real-valued predictions with observations of presence was warranted.

We showed how $\mathrm{Sk}_{\text {adj }}$ can be used with presence-only data to evaluate the relative importance of different hypotheses and the performance of different models. Our assessment of $\mathrm{Sk}_{\text {adj }}$ (by comparing it to a likelihood approach) shows that the 2 statistics perform similarly when true absence data are not available. The emergence of the PS model under the likelihood statistic for the spatial subset can be understood by looking at Fig. $6 \mathrm{~b}$ and noting that the highest predicted probability by the PS model co-occurs with the spatial subset north of Unimak Pass. While this raises interesting questions about scaling and study area extents, it does not significantly detract from the performance of $\mathrm{Sk}_{\mathrm{adj}}$.

As a measure of model performance, $\mathrm{Sk}_{\mathrm{adj}}$ does not provide the same level of validation afforded by approaches based on the reproducibility of field observations (e.g. Fielding \& Bell 1997, Guisan \& Zimmerman 2000, Segurado \& Araújo 2004). However, not all modelling efforts (and none at the spatial extents of our study) support this level of validation. Instead, validation criteria should be model specific, and should depend on the model's purpose and a set of perfor- mance criteria (Rykiel \& Edward 1996). Our goal was to demonstrate that a deductive model could be built with some quantitative rigor in the absence of rangewide survey data. Our performance criteria were quite simple - assign higher probabilities to locations were observations were made. Skewness provides both a quantitative $\left(\mathrm{Sk}_{\mathrm{adj}}\right)$ and visual interpretation (Fig. 7 ) of how well the predictive models achieve this.

\section{Steller sea lion critical habitat}

The original conceptual model of Steller sea lion habitat was likely the best possible representation of $\mathrm{CH}$ when it was designated in 1993, and was sufficient to develop initial precautionary protection measures. However, the intervening years have yielded a wealth of knowledge that can be used to develop a more quantitative and defensible definition of $\mathrm{CH}$. This is particularly timely in light of the emerging need to evaluate the effectiveness of existing and alternative protective measures (NOAA 2006), as even apparently modest differences are likely to be controversial, with significant economic consequences for the various stakeholders. 
Our deductive habitat models have greater credibility and conceptual validity over the currently designated $\mathrm{CH}$ model because they quantitatively incorporate hypotheses about sea lion foraging, as well as information about the potential processes that are responsible for suitable habitat. Regardless of the shortcomings of our ecological hypotheses, they result in a better description of at-sea sea lion sightings than the current $\mathrm{CH}$ designation. As currently designated, $\mathrm{CH}$ represents an outdated conceptual model about how sea lions are distributed at sea and should be revised to incorporate what is now known about the species.

Converting a continuous prediction to a binary representation is necessary for boundary representation. This requires the application of a threshold value. While the size of the currently designated $\mathrm{CH}$ provided a reasonable threshold for our comparison, the selection of a threshold that represents an appropriate $\mathrm{CH}$ size is far from obvious, and is one reason why receiver operating characteristic (ROC) plots and areaunder-curve (AUC) measures are attractive as validation methods (Fielding \& Bell 1997). The rank reversal of the HS1 and HS2 models relative to their $\mathrm{Sk}_{\mathrm{adj}}$ scores in the proportions test likely occurred because the thresholds applied did not capture the optimum spatial extents that would have maximized the proportion of POP observations within the predicted habitat. The $\mathrm{Sk}_{\mathrm{adj}}$ statistic, therefore, appears to integrate information across all thresholds, and may support the selection of the optimal threshold value in a manner similar to AUC and ROC plots.

The deductive approach we propose to identify the habitat used by sea lions provides an improved ecologically based definition of $\mathrm{CH}$ for a wide-ranging marine species when survey data are limited. As a presence-only approach, it defines potential rather than realized or occupied habitat and results in Type II errors (describing non-habitat as habitat), which is more precautionary than omitting existing habitat (a Type I error) (Fielding \& Bell 1997). A similar line of argument can be made regarding the $\mathrm{Sk}_{\mathrm{adj}}$ statistic. Since it uses presence-only data, it will be an inherently more conservative test (i.e. will rank models that predict presence better than models that predict absence) than presence-absence tests, particularly when absence data may be unreliable.

A comprehensive, habitat-based definition of Steller sea lion $\mathrm{CH}$ will require developing hypotheses for other relevant age and sex classes (e.g. distance to shore for juvenile animals, Fadely et al. 2005; or the removal of accessibility constraints for adult males during the winter). We have explored several such alternatives, but the lack of age or sex information in the POP data limits the extent to which age- and sex- specific models can be validated. Additional assumptions will, therefore, be required to partition the POP data into putative distributions of age and sex classes so that appropriate tests can be conducted (e.g. a distance-from-shore buffer could be used to represent the extent of breeding female movement in summer).

Habitat models with higher resolutions and smaller spatial extents will likely be required to address more local movements of sea lions. For example, the reduced spatial distribution of mature females in summer with respect to their central places (rookeries) suggests that habitat choices made during the breeding season occur at a finer scale compared to other times of the year. This is also likely to be true for juvenile sea lions, since their movements appear to be similarly restricted, particularly prior to weaning in late spring and early summer (Raum-Suryan et al. 2004). Localscale models could potentially be evaluated with the skewness test using telemetry data. Additionally, the deductive approach could be compared to more traditional model-building methods, since absence data (at least for individuals) may be easier to infer with telemetry data. The scale and extents of our analyses were appropriate for mature females during winter and would likely be suitable for adult males - while some intermediate scale would likely be appropriate for recently weaned animals.

We showed that a hypothesis-driven approach to defining habitat suitability is only limited by the existing level of knowledge, and that developing and testing hypothesized ecological mechanisms results in transparent predictions that are accessible to managers and stakeholders. Further, the skewness test $\left(\mathrm{Sk}_{\mathrm{adj}}\right)$ we propose provides a means of comparing the relative performance of different habitat representations without resorting to often unsatisfactory ways of modelling the underlying effort. All told, it is a suitable means of comparing the results of predictive models, independently of how they were derived. When applied to Steller sea lions, our analysis shows that the currently designated $\mathrm{CH}$ can be significantly improved. Our results show that explicitly stating a priori hypotheses about the relationships between species distributions and physical and biological factors, and subsequently validating the resulting predictions, moves conservation biology and resource management closer to understanding ecosystem function, and places the debate of delineating habitat where it should be-on the state of available knowledge and how the animals are believed to be distributed.

Acknowledgements. We are grateful for the support, input and ideas we have received from researchers and staff at the US National Marine Fisheries Service and the At-Sea Processors Association, in particular L. Connors, L. Fritz, A. 
Hollowed, S. Hinckley and E. Logerwell. S. Mizroch provided helpful information regarding the Platform of Opportunity data. We thank R. Joy for several detailed reviews and fruitful discussions of the skewness statistic, an idea that emerged from conversations with C. Walters. We also thank K. Bodtker, K. Kaschner and A. Winship for insightful comments during the various stages of model and manuscript development. This study was supported by grants from NOAA, the Pollock Conservation and Cooperative Research Center (University of Alaska Fairbanks) and the North Pacific Marine Science Foundation through the North Pacific Universities Marine Mammal Research Consortium. Initial development was supported through in-kind contributions from Facet Decision Systems, Inc. (Vancouver, British Columbia).

\section{LITERATURE CITED}

Austin MP (2002) Spatial prediction of species distribution: an interface between ecological theory and statistical modelling. Ecol Model 157:101-118

AVISO (Archiving, validation and interpretation of satellite oceanographic data) (2005) Available at: www.aviso. oceanobs.com, accessed February 14, 2005

Bakun A (1996) Patterns in the ocean: ocean processes and marine population dynamics. California Sea Grant, La Jolla, CA

Beyer HL (2004) Hawth's analysis tools for ArcGIS. Available at: www.spatialecology.com/htools, accessed November 11, 2007

Bradshaw CJA, Higgins J, Michael KJ, Wotherspoon SJ, Hindell MA (2004) At-sea distribution of female southern elephant seals relative to variation in ocean surface properties. ICES J Mar Sci 61:1014-1027

Brandon EAA (2000) Maternal investment in Steller sea lions in Alaska. PhD thesis, Texas A\&M University, Galveston, TX

Chilvers BL, Wilkinson IS, Duignan PJ, Gemmell NJ (2005) Summer foraging areas for lactating New Zealand sea lions Phocarctos hookeri. Mar Ecol Prog Ser 304:235-247

> Ciannelli L, Robson BW, Francis RC, Aydin K, Brodeur RD (2004) Boundaries of open marine ecosystems: an application to the Pribilof archipelago, Southeast Bering Sea. Ecol Appl 14:942-953

Eastman JR 2001. IDRISI Release 2-Guide to GIS and image processing, 32.20 edn. Clark University, Worcester, MA

ESRI (Environmental Systems Research Institute) (2005) ArcGIS. Environmental Systems Research Institute, Redlands, CA

Fadely BS, Robson BW, Sterling JT, Greig A, Call KA (2005) Immature Steller sea lion (Eumetopias jubatus) dive activity in relation to habitat features of the eastern Aleutian Islands. Fish Oceanogr 14:243-258

Fielding AH, Bell JF (1997) A review of methods for the assessment of prediction errors in conservation presence/ absence models. Environ Conserv 24:38-49

> Gende SM, Sigler MF (2006) Persistence of forage fish 'hot spots' and its association with foraging Steller sea lions (Eumetopias jubatus) in southeast Alaska. Deep-Sea Res II 53:432-441

Gregr EJ, Trites AW (2001) Predictions of critical habitat for five whale species in the waters of coastal British Columbia. Can J Fish Aquat Sci 58:1265-1285

Gregr EJ, Nichol L, Watson JC, Ford JKB, Ellis GM (2008) Estimating carrying capacity for sea otters in British Columbia. J Wildl Manage 72:382-388

Guinet C, Dubroca L, Lea MA, Goldsworthy S and others
(2001) Spatial distribution of foraging in female Antarctic fur seals Arctocephalus gazella in relation to oceanographic variables: a scale-dependent approach using geographic information systems. Mar Ecol Prog Ser 219: 251-264

Guisan A, Zimmerman NE (2000) Predictive habitat distribution models in ecology. Ecol Model 135:147-186

Hilborn R, Mangel M (1997) The ecological detective: confronting models with data. Princeton University Press, Princeton, NJ

Hirzel AH, Hausser J, Chessel D, Perrin N (2002) Ecologicalniche factor analysis: How to compute habitat-suitability maps without absence data? Ecology 83:2027-2036

Hui CA (1985) Undersea topography and the comparative distributions of two pelagic cetaceans. Fish Bull (Wash DC) 83:472-475

Kaschner K, Watson R, Trites AW, Pauly D (2006) Mapping world-wide distributions of marine mammal species using a relative environmental suitability (RES) model. Mar Ecol Prog Ser 316:285-310

Kruse GH, Morgen C, Krygier EE, Lloyd DS and others (2001) A review of proposed fishery management actions and the decline of Steller sea lions Eumetopias jubatus in Alaska: a report by the Alaska steller sea lion restoration team. Alaska Department of Fish and Game, Juneau, AK

Lea MA, Dubroca L (2003) Fine-scale linkages between the diving behaviour of Antarctic fur seals and oceanographic features in the southern Indian Ocean. ICES J Mar Sci 60: 990-1002

> Logerwell EA, Aydin K, Barbeaux S, Brown E and others (2005) Geographic patterns in the demersal ichthyofauna of the Aleutian islands. Fish Oceanogr 14:93-112

Loughlin TR, Perez MA, Merrick RL (1987) Eumetopias jubatus. Mammal Spec 283:1-7

Loughlin TR, Perlov AS, Baker JD, Blokhin SA, Makhnyr AG (1998) Diving behavior of adult female Steller sea lions in the Kuril Islands, Russia. Biosphere Conserv 1:21-31

Matthiopoulos J, McConnell B, Duck C, Fedak M (2004) Using satellite telemetry and aerial counts to estimate space use by grey seals around the British Isles. J Appl Ecol 41:476-491

McConnell BJ, Fedak MA, Lovell P, Hammond PS (1999) Movements and foraging areas of grey seals in the North Sea. J Appl Ecol 36:573-590

> Merrick RL, Loughlin TR (1997) Foraging behavior of adult female and young-of-year Steller sea lions in Alaskan waters. Can J Zool 75:776-786

> Milette LL, Trites AW (2003) Maternal attendance patterns of lactating Steller sea lions (Eumetopias jubatus) from a stable and a declining population in Alaska. Can J Zool 81:340-348

NMFS (National Marine Fisheries Service) (2005) Appendix D-EFH text and map descriptions for federally managed species of the alaska region. In: Final environmental impact statement for essential fish habitat identification and conservation in Alaska. NMFS, United States Department of Commerce, Seattle, WA

NMML (National Marine Mammal Laboratory) (2006a) Steller sea lion research-Databases. Available at: http://nmml. afsc.noaa.gov/AlaskaEcosystems/sslhome/stellerhome.html, accessed July 7, 2006

NMML (National Marine Mammal Laboratory) (2006b) Published Steller sea lion count data. Available at: http://nmml. afsc.noaa.gov/AlaskaEcosystems/sslhome/stellerhome.html, accessed July 7, 2006

NOAA (National Oceanic and Atmospheric Administration) (1990) West coast of North America coastal and ocean 
zones strategic assessment: Data atlas. Invertebrate and fish volume. NOAA OMA/NOS Assessment Division, Strategic Assessment Branch, Rockville, MD

NOAA (National Oceanic and Atmospheric Administration) (2006) Steller sea lion mitigation committee, reference materials, November 8, 2006. Available at: www.fakr. noaa.gov/sustainablefisheries/sslmc/, accessed January 8, 2007

Ottaviani D, Lasinio GJ, Boitani L (2004) Two statistical methods to validate habitat suitability models using presenceonly data. Ecol Model 179:417-443

Pearce JL, Boyce MS (2006) Modelling distribution and abundance with presence-only data. J Appl Ecol 43:405-412

Pitcher KW, Rehberg MJ, Pendleton GW, Raum-Suryan KL, Gelatt TS, Swain UG, Sigler MF (2005) Ontogeny of dive performance in pup and juvenile Steller sea lions in Alaska. Can J Zool 83:1214-1231

Raum-Suryan KL, Pitcher KW, Calkins DG, Sease JL, Loughlin TR (2002) Dispersal, rookery fidelity, and metapopulation structure of Steller sea lions (Eumetopias jubatus) in an increasing and a decreasing population in Alaska. Mar Mamm Sci 18:746-764

Raum-Suryan KL, Rehberg MJ, Pendleton GW, Pitcher KW, Gelatt TS (2004) Development and dispersal, movement patterns, and haulout use by pup and juvenile Steller sea lions (Eumetopias jubatus) in Alaska. Mar Mamm Sci 20: 823-850

Redfern JV, Ferguson MC, Becker EA, Hyrenbach KD and others (2006) Techniques for cetacean-habitat modeling. Mar Ecol Prog Ser 310:271-295

Rykiel J, Edward J (1996) Testing ecological models: the meaning of validation. Ecol Model 90:229-244

Segurado P, Araújo MB (2004) An evaluation of methods for

Editorial responsibility: David Ainley,

Los Gatos, California, USA modelling species distributions. J Biogeogr 31:1555-1568 Sinclair EH, Zeppelin TK (2002) Seasonal and spatial differences in diet in the western stock of Steller sea lions (Eumetopias jubatus). J Mammal 83:973-990

Sjöberg M, Ball JP (2000) Grey seal, Halichoerus grypus, habitat selection around haulout sites in the Baltic Sea: Bathymetry or central-place foraging? Can J Zool 78: 1661-1667

Smith GB (1981) The biology of walleye pollock. In: Hood DW, Calder JA (eds) The eastern Bering Sea shelf: oceanography and resources. U.S. Department of Commerce, Washington, DC, p 527-551

Smith WHF, Sandwell DT (1997) Global sea floor topography from satellite altimetry and ship depth soundings. Science 277:1956-1962

Southwell CJ, Kerry KR, Ensor PH (2005) Predicting the distribution of crabeater seals Lobodon Carcinophaga off east Antarctica during the breeding season. Mar Ecol Prog Ser 299:297-309

Trites AW, Porter BT (2002) Attendance patterns of Steller sea lions (Eumetopias jubatus) and their young during winter. J Zool 256:547-556

Trites AW, Calkins DG, Winship AJ (2006) Diets of Steller sea lions (Eumetopias jubatus) in Southeast Alaska from 1993-1999. Fish Bull 105:234-248

Wolotira RJ Jr, Sample TM, Noel SF, Iten CR (1993) Geographic and bathymetric distributions for many commercially important fishes and shellfishes off the west coast of North America, based on research survey and commercial catch data, 1912-84. NOAA Tech Mem NMFS-AFSC, C55.13/2:6

Zar JH (1996) Biostatistical analysis, 3rd edn. Prentice Hall, Englewood Cliffs, NJ

Submitted: July 5, 2007; Accepted: April 7, 2008

Proofs received from author(s): August 5, 2008 